ture and the silk is closely overland, making them ver tough and hard. The most remarkable cocoon in thi respect is that of a small species found not uncom-
monly in the forests of the Upper Amazon and its tributaries $(\boldsymbol{d})$. It is a Saturniid, but of what specie is not known. The cocoon often hangs horizontally and at right angles from the thick stem and the exit of the moth is properly a part of the stem. The material is so hard and tough as to make it impossible to force a pin through it by the head; if the fingers are strong enough the pin will bend. This nut-like case would almost seem to be impervious to the attack of bird or ichneumon fly. However, some of the lat ter pierce oak and hickory for several inches and some of the parrots might use their bills successfully upon it. (The writer had his thumb pinched once by a parrot; a cocoon might even be of thin iron and succumb.)

The bag worms employ not alone their silk-spinning powers. Stems and parts of leaves, twigs, bits of bark and other material are used to mix with or lay over the silken strands. Our own common species, Thy ridopteryx, covers the outside of its "bag" with bits of leaves an'd stems, and an examination of its cocoon will often determine upon what tree the caterpillar lived. Some of the tropical bag worms (they are sometimes called basket worms) have very remarkable larval and pupal cocoons. Several species build a. long, narrow case not unlike a cigar in shape and color, the texture very tough, one of which is shown at $e$ and $f$. Another covers its cocoons with bits of grass stems, cutting the straws off the desired length and arranging and fastening ther in regular form so as to complete the cylinder $(g)$. Still another makes a double cocoon and fills the space between them with sticks, the stems of leaves cut very short $(h)$. In doing this it may spin the outer coat, then drag the sticks within it, and after thus coating the inside line the whole with the inner case. Or it may make
the inner case first, cover it with sticks and then reach far enough out to spin the outer coat over all. The result is certainly a tough, almost impregnable protection, and shows the height of skill in cocoon making. The cocoons of most moths are, in general, not unlike that of the tropical races of the domestic silk worm, a non-rigid, elliptical case, more or less thick, with outer strands holding it in place. Some are pure white in color, others pale or dark brown, some greenish or dull red, none of varied or high color. Some caterpillars cut away the bark of the tree or the dead wood so as to imbed the cocoon in it at least half way; others seek a hollow stem or other narrow cell and conform the cocoon to its shape.

Gregarious species often build a mass of cocoons closely united, the outer strands inextricably entwined one with another so that it appears rather more like a common cover over all than separate cells. The silk-spinning habit is common with all nocturnal Lepidoptera. None, in fact, are without it, even those that burrow in the ground, as the hawk moths (Sphin gid $(e)$; for, upon forming the earthen cell at the end of the caterpillars' downward burrow, they line this with a thin layer of silk varnished with sericin that is often shining black.

Many insects besides the Lepidoptera are silk spinners; excepting nearly all of the Diptera and many Coleoptera, insects of the orders having inactive pupæ employ this power either to make cocoons or to line their pupal retreats.

The sawfly slugs (Tenthredo) line their earthen pupal cells with a shining, silken coat that is often beetle larve as certain weevils (Curcutionide) and beetle larke, as certain weevils ( leaf beetles (Chrysomelid $C$ ) do the same, but less perand Braconide) are often excellent and independent cocoon builders, the larger species nearly always covering themselves with fine, parchment-like silken cases made within their larval and pupal retreats, while the small, almost microscopic species make cocoons that in miniature greatly resemble those of the domestic silk worm; they have the same shape, color (white and yellow), and texture $(k)$. Some of these also kuild an irregular parchment-like pupal case within or contiguous to the insect in which they passed their larval existence. The bees, wasps, hornets, and ants and the solitary hornets, as the mud-daubers, the diggers, etc., nearly all make cocoons within their nests and the cells thereof; these are also parchment-like. 'The so-called eggs of ants, often seen being carried from an exposed ant hill, are the cocoons of the helpless larvæ, and by opening a mud wasp's nest the brown, thick-at-one-end cocoons may be extracted that are nearly typical of those of the solitary Hymenoptera.

The caddie flies (Trichoptera) are excellent cocoon builders; the larvæ and pupæ under water are not alone protected by tough cases but they are fashioned with a resemblance to shells, stones, sticks, etc., and often these articles are used in the effort to make the cocoons unseen. Tiny pebbles are fitted together so closely as to leave hardly a visible opening between them; small sticks are fenced around in three-corner pig-pen fashion, or like bundles, end to end, cut all of a length, and the interiors of these cases are lined thickly with silk and a head-end pliable opening is extended that can be drawn in and closed.

The useful larvæ of the golden-eyed, gauze-winged flies (Chrysopider) are cocoon builders, their small, nearly round, silken balls resembling pills fastened to a leaf. They are cut open evenly at one end, permitting a lid-like opening for the exit of the fly, similar to the cocoons of Apanteles. It is here remarkable that the insect spins its cocoons from anal glands and not by the mouth-parts.

The larva of the flea, in chinks and crevices, makes a flat, spread-out pupal covering, the floor of which is the object to which it is attached, appearing more like a low, silken tent than a true cocoon.

\title{
THE DURATION OF LIFE ON THE EARTH.
}

\author{
THE INFLUENCE OF SEA AND CARBON DIOXIDE.
}

BY J. C. GREGORY, B.SC., A.I.C.

IT has been calculated that the combustion of coal throws every year into the atmosphere $2.4 \times 10^{3}$ tons of carbon dioxide. If this figure is accepted, it works out to about 76 tons per second. On an average, then, there is an addition of about 76 tons of carbon dioxide to the atmosphere from the burning of coal in every second of time. If these 76 tons of carbon dioxide were all massed together under average atmospheric conditions they would occupy about 8,616,000 gallons. Carbon dioxide being about one and one-half times as heavy as air, it might be thought that all the gas thus poured into the air would tend to settle to the bottom of the atmosphere and form a thick layer on the surface of the earth. In the well-known Poison Valley of Java, the accumulation of carbon dioxide tends to suffocate animals that enter it. In the Grotto del Cane near Naples dogs are apt to be asphyxiated by the underlying layers of carbonic acid gas. The exceptional character of such places, however, tends to prove that atmospheric carbon dioxide does not form a bottom layer. The gas really spreads itself throughout the atmosphere.

Now although there is a constant flow of carbon dioxide into the air from organic and iniorganic sources, the total amount of this gas in the atmosphere remains remarkably constant. It appears to be increasing slightly, but only very slightly. The total amount of carbon dioxide in the air has been computed to be about 1000 times the quantity produeed annually by the burning of coal. Its total weight is therefore about $2.4 \times 10^{12}$ tons. The most recent estimate of the total population of the world recent estimate of the total population of the world suggests the figure $1.5 \times 10^{3}$. fore, about 1,600 tons of carbon dioxide in the atmofore, about 1,600 tons of carbon dioxide in the atmo-
sphere. Compared with the amount of carbon dioxide expired by the total population of the world in one year, the total amount of carbon dioxide in the atmosphere is very great. Roughly speaking, 1,000,000 human seings expire about 2.5 tons of carbon dioxide in one hour. This is only an approximate figure, but it is enough to indicate that the respiration of the population of the globe would take a long time to produce the total amount of atmospheric carbon dioxide. According to this figure, the $1.5 \times 10^{2}$ inhabitants of the globe daily expire 90,000 tons of the gas. This would amount to $32,850,000$ tons in one year. Approximately 71,000 years would therefore elapse before the total amount of carbon dioxide in the air could be obtained by the breathing of the present population of the globe. In this approximate calcula

is taken of the respiration of beasts.

The carbon dioxide produced from all sources and poured into the atmosphere tends to mix uniformly with the other gases of the air. But just as cold water from the North Pole or the warm waters from the Gulf Stream constitute definite currents before they are completely mixed up with the main body of oceanic water, so there tends to be a larger proportion of carbon dioxide in the neighborhood of the places where it is generated. Thus in the air of the Grotto del Cane there is a relatively large proportion of carbon dioxide. It takes time for the generated gas to diffuse away and scatter uniformly through the atmosphere. In the same way the proportion of carbon dioxide is greater in the neighborhood of cities and towns than it is in unpopulated districts.

This is more particularly the case-in the rooms and houses of towns and cities. When the carbon dioxide breathed out by their inhabitants is more or less shut in by doors and windows, it naturally takes longer for the gas to diffuse away. One object of ventilation is to hasten the mixing of the expired carbon dioxide with the main body of the atmosphere. To a person entering from the open air,' a room begins to "feel close" when in every 10,000 cubic feet of air there are six feet of carbon dioxide. Under these cireumstances the amount of carbon dioxide contained in a room 50 feet long, 10 feet high, and 20 feet broad would be about equal in volume to a ball $114 / 5$ inches in diameter. It is usual to take this as the maximum amount of carbon dioxide allowable. This proportion of the gas is perhaps not dangerous in itself, but it acts as an index of the pollution of the air. It is the volatile erganic matters expired along with the carbon dioxide that make the room unhealthy. Most people suf fer from headache and depression in an atmosphere containing 15 cubic feet of carbon dioxide in every 10,000 cubic feet of air. Too great a proportion of carbon dioxide is, of course, in itself inimical to health and a great excess will produce suffocation. But th usual effects of vitiated atmospheres are mainly due $t$ other products of decomposition. The smell of such vitiated air is due to these "volatile ptomaines.".

It is an interesting fact that the proportion of atmos pheric carbon dioxide is usually greater on mountain tops than lower down. At the top of Mont Blanc the carbon dioxide is present in more than one and three- quarter times its average proportion. Ordinary air contains, on an average, rather more than three and one-quarter pints of carbon dioxide in every ten thousand pints of air. In every ten thousand pints of air of carbon dioxide. The proportion of carbon dioxide at the top of Mont Blanc just about reaches the limit below which it is considered desirable to keep the ca bon dioxide in rooms. In the case of the mountain air, however, the carbon dioxide does not indicate respiratory pollution, and is probably connected with the comparative or total absence of vegetation. Carbon dioxide is a food of green plants, and where there is much regetation it is accordingly drawn off from the air. By means of the green coloring matter (called chlorophyl), and assisted by the sunlight, plants remove the carbon from the carbon dioxide and breath out the oxygen again. "Since sunlight is necessary to enable plants to do this, the proportion of carbon diox ide in the air usually rises at night. Foggy weathe often produces a slight increase, which may be partly due to the cutting off of the sunlight.

The constant withdrawal of carbon dioxide from the air by plants helps to balance its emission into the air from all the various sources. Although the amount of carbon dioxide in the air appears to be slightly increasing, there is a striking constancy in its total amount. It seems very remarkable that the influx and efflux of the gas into and from the air should so well balance one another. It has recently been pointed out that the sea acts as a regulator of the amount of atmospheric carbon dioxide. It does this by dissolving a proportion of the excess of the gas over the normal amount; and, under certain circumstances, restoring sume to make good any deficiency.

In view of the relatively great disturbance of the balance between the carbon dioxide emitted into and withdrawn from the atmosphere by the burning of coal, this regulative effect becomes an important factor in the economy of Nature. Many investigators think that a doubling of the proportion of carbon diox ide normally present in the atmosphere would almost render the air unfit for continued respiration. As already seen, about 71,000 years would elapse befor the respiration of the present population of the globe would convert the approximately 3 volumes of carbon dioxide per 10.000 of air into twice that amount. Since the carbon dioxide produced annually by the combustion of coal appears to be about 0.001 of the total vol- 
me in the atmosphere, 1,000 years of coal consumption at the present rate would produce the same doubling. Assuming that the action of vegetation, etc. fairly well balances the effects of respiration, decay, and other processes that pour carbon dioxide into the air, the relatively great production of the gas by the combustion of coal might become a serious matter.

To understand the regulative action of the sea imag. ine a cubical vessel having a capacity of 20,000 cubic feet. - If this ressel is half full of pure water and half full of air it will contain 10,000 cubic feet of each. Suppose that the vessel is completely closed in, and that the air contains three cubic feet of carbon diox ide. That is, if all the carbon dioxide spread through the air were collected together it would occupy three cubic feet. This amount represents, approximately, the average amount of carbon dioxide in the air. The air, including the carbon dioxide, will proceed to dissolve in the water. The dissolved air will gradually spread through the water until the water has dissolved as much as it can take up. Two processes are really concerned. In the first place air dissolves in the water-passing from the space above into the water At the same time, some of the dissolved air escapes from the water into the upper space. As long as more air passes from the space above to the water than from the water to the space above, the water continues to extract air from the upper space. It is evident that as long as the dissolved air continues to increase in amount, the amount of air escaping from the water in a given time will continue to increase, because there is more air to escape. In course of time the two processes balance one another-the exports ultimately equal the imports-and the water now contains as much air as it can take up (under the circumstances). When this equilibrium is attained, the pressures exerted by the dissolved and atmospheric air are equal to one another.

Now consider the carbon dioxide alone-ignoring the other gases. As a matter of fact, the carbon dioxide behaves just as if it alone occupied the whole space. When the water has taken up-dissolved-as much carbon dioxide as it can, about one and a half cubic feet of the gas is dissolved in the water and the remaining one and a half feet remains in the air above If there had been six cubic feet of carbon dioxide to If there had been six cubic feet of carbon dioxide to
begin with, three of these would have been dissolved in the water. The water and the air above contain about half each of the carbon dioxide. This is when the volumes of the water and air are equal. If the volume of the water were twice that of the air, it would dissolve about two-thirds of the carbon dioxide; and the remaining third remain in the air, and so on. If now a little more carbon dioxide is introduced into the air above, some more dissolves in the water unt:1 ir, is again equally divided between the equal volumes cf water and air. If a little carbon dioxide is removed from the air above, some carbon dioxide escapes from the water until the remaining gas is again equally divided between the water and the air. Thus the water tends to keep the amount of carbon dioxide in the air above constant, dissolving more when the amount increases and giving up some when the quantity decreases. It cannot, of course, keep it perfectly constant, but if there is a very large quantity of water it can do much in this direction.

The very large total volume of the sea has a very considerable effect in maintaining the constancy of the proportion of carbon dioxide in the air. It has heen calculated that the sea contains about twentyseven times as much carbon dioxide as the atmosphere. The amount of carbon dioxide absorbed by the sea is affected by the salts dissolved in it, so that the preceding paragraphs do not give a complete account of the matter. The water of the North Atlantic has been shown to contain 49 cubic centimeters of carbon diox. ide per liter. This is equivalent to 400 parts per 10,000. This carbon dioxide contained in sea water may be for practical purposes divided into two parts, one being regarded as existing in combination as carbonates or bicarbonates and the other being free tc diffuse through and out of the water just as in the case of carbon dioxide dissolved in pure water. These two portions are not absolutely unconnected; it is well known that bicarbonates like those of sodium and calcium tend to decompose in solution, and that excess of carbon dioxide converts some carbonate into bicarbonate, but sea water always contains some free "carbon dioxide.

Equilibrium between this free and the atmospheric carbon dioxide is attained when the pressures of the two are equalized. As just seen, in the case of pure water the pressure of the dissolved carbon dioxide be comes equal to the pressure of the atmospheric carbo dioxide when the volume of the dissolved gas per lite of solution is practically equal to its volume in a lite of air. A constant interchange thus takes place be tween the surface of the sea (and of other waters) and the air above it, according as the pressure of the carbon dioxide is greater in the air or in the water. Any deviation from the normal proportion of carbo Any deviation from the normal proportion of carbon
dioxide in the air produces a compensating effect by altering the pressure of the atmospheric portion of the gas which results in absorption by the sea of some of the excess, or in the introduction of some of the dissolved gas into the air to make good the deficiency. Investigation appears to indicate that the pressure of carbon dioxide is less over the surface of the sea than cver the land. If this is so, the accumulation of carbon dioxide in the air may be regarded as being continuously retarded by the constant absorption by the sea of any excess over the normal quantity. Since the presence of any considerable excess of carbon dioxide cver its present amount might seriously interfere with animal life, it is evident that the sea may play a very important part in determining the length of the period for which the earth can continue to be habitable by man.

\section{Coxtegpandente.}

\section{THE WADAGAHI STEAM TURBINE.}

To the Editor of the Scientific American:

The article in the Supplement of May 29th, page 339 , on turbine propellers interested and surprised me. Ii would seem, to an engineer up a tree, that the obvious way to transmit the motion of the steam turbine to the propeller, at any desired proportion of speed, would be by means of water (with a suitable lubricant in solution) forced by a rotary pump connected with the turbine shaft, to a motor on the propeller shaft. Oî course, oil might do, though its superiority is doubtful. Properly arranged, the loss in transmission should be very moderate. Furthermore, the relative speed of the propeller could be perfectly regulated by a side valve for letting part of the fluid from the pump into the return pipe without entering the motor. This, theoretically at least, involves no loss of power, except to the propeller.

S. Tideman.

Peru, Ill.

\section{PROOF THAT A CONIC SECTION MUST \\ BE DESCRIBED UNDER GRAVITY.}

To the Editor of the ScIENTIFIC AMERICAN:

To prove that a particle, moving under the action of a central attractive force which varies inversely as the square of the distance, describes a conic section of which the center of force is a focus:

Let $S$ be the center of force, $P$ the position of the particle, and $P T$ its direction of motion at any moment. Also let $Q$ be the position of the particle and $T Q$ its direction at a subsequent period.

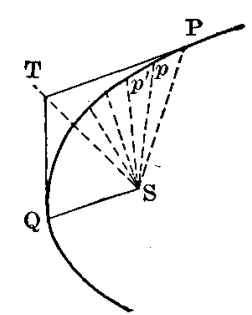

Suppose the angle $P S Q$ to be divided up into an in. definite number of minute equal angles $p \$ p^{\prime}$ Denote

and the force length $s p$ by $r$

Then, by hypothesis

along $s p$ by $f$

(A)

$$
f \S \frac{1}{r^{2}}
$$

Now, since the angles $p S p^{\prime} \ldots$ at $S$ are equal, we have area of $\triangle p S p^{\prime} \& \boldsymbol{r}^{2}$

But, by a general law of motion the area of $\Delta p s p$ is proportional to the time $(t)$ taken to describe it

(B) Hence $t \& r^{2}$

Multiplying (A) and (B) we have $f t \& \frac{\boldsymbol{r}^{2}}{-}$, that is, is

constant

In other words, while the particle describes equal minute angles about $S$, it is acted upon by a constant amount of force directed toward $S$; and it is not diffcult to see that the resultant of all these evenly-dis tributed equal forces must be through $\mathbb{S}$, and must $b$ sect the angle $P S Q$ traced out by this particle.

But this resultant, inasmuch as it effects a change of motion in the particle from $P T$ to $T Q$ must pas through $T$.

Hence, TS bisects the angle PSQ, which is a genera property of conic sections with $S$ as a focus. Imimo S. Allen.

London Institution, Finsbury Circus, E. C.

\section{THE CURIOSITIES OF NUMBERS.}

\section{To the Editor of the Scientific American:}

It is curious that the writer of just the very article that absolutely denies the curiosity of numbers and emphasizes the rigid truth of mathematics at the same time commits himself by demonstrating the greatest of all the curiosities any of the other articles that have come under my notice as yet have revealed.

in the Scientific American of April 10th, Mr. D. M.

Morris, while in the act of explaining the mystery of how it is that the sum of the 9 digits, doubled, and the last term deducted from the product, equals the square of the last term, states that the sum of any like series is half the sum of the first and the last terms divided by 2 and multiplied by the last term.

I am sure that many of the readers of the ScIEnTIFIC American who are less advanced in mathematics must consider the above statement rather emphasizing the theory of curiosity of numbers, whereas those better acquainted with said science soon see what Mr. Morris really means to say.

As the case in question is the simplest application of arithmetical progression, the formula is written $n(a+n)$

$s=-$ where $a$ is the first term, $n$ the number of terms or value of slast term, whereas according to Mr. Morris the same formula would look like this $n(a+n)$

$S=\frac{(a+n)}{4}$ wich of course is wrong.

I have no doubt that Mr. Morris knows different from what he writes, but it is hard refraining from pointing out a serious error in a statement of this kind, especially where it takes the form of censure. Great care should be taken in putting explanations correctly and very plainly.

Shanghai, China.

\section{ESTIMATION OF NITRATES AND} NITRITES IN WATER.

THE nitrates and nitrites contained in water can be estimated either together or separately. The reagents which act similarly with both compounds include:

First. Diphenylamine sulphate, a few drops of which in presence of a drop or two of the nitrated water and of 1 cubic centimeter of sulphuric acid produce a blue coloration, which shades into yellow if the solution is too concentrated.

Second. Carbazol, or diphenylene-imine, which gives a bluish-green color

Third. Brucine, which gives a fugitive red color.

Fourth. The reagent of Grandval and Lajoux, consisting of sulphuric acid with 7 per cent of phenol which is employed as follows:

To one drop of suspected water 1 cubic centimete of the reagent is added. Distilled water is added to niake 8 or 10 cubic centimeters and ammonia is the added in excess. The result is the formation of am monium picrate, which colors the liquid yellow. In order to estimate the nitrates and nitrites, 10 cubi centimeters of the water is evaporated to dryness, and the residue is wet with 10 drops of the reagent and a little water. Ammonia is then added in excess, and the mixture is diluted to 50 cubic centimeters. The tint obtained is compared with a scale of tubes containing solutions prepared by diluting a standard solution of potassium nitrate which has been treated with the re agent in the same manner.

The reagents used for the estimation of nitrites alone are:

First. Antipyrine, which gives, with nitrites and su phuric acid, a green or bluish green coloration, due to nitroso-antipyrine.

Second. The reagent of Griess, sulphanilic acid and naphthylamine. This reagent produces a red color with nitrites, but is too sensitive for ordinary work.

Third. Aniline acetate, giving a blood-red color in presence of nitrites and sulphuric acid at the tempera ture of ebullition.

Fourth. Metaphenylene-diamine hydrochlorate.

Fifth. Potassium iodide and starch.

Tabuteau recommends the last two reagents, for example: To 10 cubic centimeters of a solution of silver nitrite containing 0.406 gramme per liter are added 5 drops of a solution of 1 part of metaphenylenedia mine hydrochlorate in 200 parts of water and 5 cubic centimeters of a 10 per cent solution of sulphuric acid. The mixture is shaken and heated to boiling over the water bath. A brown coloration is produced by the formation of Bismarck brown. The mixture is by the formation of Bismarck brown. The mixture is meters of the liquid is placed in a tube and gradually decreasing quantities are placed in other tubes, which are filled up with water to 50 cubic centimeters in order to obtain a scale of comparison. The same operation is repeated on the suspected water, and the tint produced is compared with the scale thus estab. lished. The proportion of nitrites in the water can be obtained by a very simple calculation. In the starch iodine method 100 cubic centimeters of the water are mixed with 20 cubic centimeters of 10 per cent hydrochloric acid arid 2 or 3 cubic centimeters of starch paste. Nitrous acid and oxygen are disengaged. Four or five grammes of potassium carbonate are added, causing an evolution of carbon dioxide which expels the oxygen; 20 cubic centimeters of a solution of po- 